\title{
EVALUATION OF ANNUAL MODIS PTC DATA FOR DEFORESTATION AND FOREST DEGRADATION ANALYSIS
}

\author{
Y. Gao ${ }^{\text {a, }}$, A. Ghilardi ${ }^{\text {a }}$, J. F. Mas ${ }^{\text {a }}$, J. Paneque-Galvez ${ }^{\text {a }}$, M. Skutsch ${ }^{\text {a }}$ \\ ${ }^{a}$ CIGA-UNAM, Antigua Carretera a Pátzcuaro 8701, c.p. 58190, Morelia, México - (ygao, aghilardi, jfmas, mskutsch, \\ jpaneque)@ciga.unam.mx
}

Commission II, WG II - 1

KEY WORDS: MODIS VCF, Percent Tree Cover (PTC), deforestation, forest degradation, regeneration, reforestation, SPOT-5

\begin{abstract}
:
Anthropogenic land-cover change, e.g. deforestation and forest degradation cause carbon emissions. To estimate deforestation and forest degradation, it is important to have reliable data on forest cover. In this analysis, we evaluated annual MODIS Percent Tree Cover (PTC) data for the detection of forest change including deforestation, forest degradation, reforestation and revegetation. The annual MODIS PTC data $(2000$ - 2010) were pre-processed by applying quality layer. Based on the PTC values of the annual MODIS data, forest change maps were produced and assessed by comparing with the data from visual interpretation of SPOT-5 images. The assessment was applied to two case-studies: Ayuquila Basin and Monarch Reserve. Results show that the detected deforestation patches by visual interpretation are roughly 4 times in quantity more than those by MODIS PTC data, which can be partially due to the much higher spatial resolution of SPOT-5, being able to pick up small deforestation patches. This analysis found poor spatial overlapping for both case-studies. Possible reasons for the discrepancy in quantity and spatial coincidence were provided. It is necessary to refine the methodology for forest change detection by PTC images; also to refine the validation data in terms of data periods and forest change categories to ensure a better assessment.
\end{abstract}

\section{INTRODUCTION}

Scientific research has proved that deforestation and forest degradation is a large source for greenhouse gas (GHG) emissions (Corbera et al. 2010, Van der Werf et al. 2009). REDD+ was launched by UNFCCC to tackle the problem of GHG emission by reducing deforestation and forest degradation. In Mexico, there are pilot projects for REDD+, for which, it is important to construct baselines for deforestation and forest degradation. The Secretariat of Environment and Natural Resources of Mexico (www.semarnat.gob.mx) has issued figures on deforestation rates, estimating that the annual deforestation was 155,000 ha between 2002 and 2007 (SEMARNAT 2010). There are not yet official figures for the annual rate of forest degradation. To evaluate forest degradation, two estimates are required: the spatial extent of the affected area and the average annual loss of biomass per hectare affected. The spatial extent is difficult to observe using remote sensing technology even with images of high spatial resolution because forest degradation is not a change in land cover but a change in biomass density. However, gradual variations in canopy cover may be used as a proxy variable for measuring changes in aboveground biomass density in forests and woodlands (FAO 2011, Bailis et al. 2015). The quantification of forest degradation at national level is necessary to measure GHG emissions from the land use/cover change in forestry sector. It is important to develop a methodology that can provide an accurate estimation of forest degradation which could be affecting a much larger area than deforestation in tropical countries (Skutsch et al. in preparation).
Gao et al. (2015) shows that in the case study of Ayuquila Basin, one date MODIS PTC data (2010) present significantly different values in tree cover between categories of temperate forest and non-forest however didn't differentiate tropical dry forest from non-forest categories. Thus MODIS PTC data can be potentially used to detect deforestation of temperate forest but not for tropical dry forest. In Monarch Reserve, one date MODIS PTC data (2010) did not present significantly different values in tree cover for temperate forest in different degradation stages (dense, moderately degraded, heavily degraded), and thus single date PTC data is not suitable to detect forest degradation of temperate forest. To monitor forest degradation, time series analysis is needed in order to detect the gradual changes in forest cover. This paper presents the results of forest change including deforestation, forest degradation, reforestation, and revegetation detected by annual MODIS PTC and its verification by comparing with the results from visual interpretation of SPOT-5 images.

The objective of this paper is to test if annual MODIS PTC data can be used to detect forest cover change, and to establish a reference emission level for Mexico as necessary under REDD+.

\section{STUDY AREA, DATA AND METHODS}

\subsection{Study area and data}

The two case studies are Ayuquila Basin in Jalisco State and Monarch Reserve in Michoacán state. The Ayuquila Basin is located in western Jalisco. Shifting cultivation and cattle grazing often take place in the basin, resulting in degradation

\footnotetext{
* Corresponding author
} 
and loss of carbon stocks. The main vegetation types are tropical dry forest, oak, oak-pine and pine forests, with isolated patches of montane cloud forest (Morales-Barquero et al. 2014, Jardelet et al. 2013, Ghilardi et al. 2012).

The Monarch Reserve is covered mainly by fir (Abiesreligiosa) and fir-pine (Abies-Pinus) forests at the higher elevations, and pine-oak (Pinus-Quercus) and other broad-leaved forests in the lower areas. In the last 20 years, the study area has experienced deforestation and forest degradation caused mainly by illegal logging (Honey-Rosés 2009, Navarrete et al. 2011, Brower et al. 2011, Vidal et al. 2013).

The data used for this study include annual MODIS PTC data from $2000-2010$. PTC is the first scientific data layer of MODIS Vegetation Continuous Fields (VCF) which gives the per cent of a pixel covered by tree canopy (Townshend et al. 2011). This study also includes land cover maps for the Ayuquila Basin and the Monarch Reserve. The land cover maps for the Ayuquila Basin were generated by visual interpretation of SPOT-5 images obtained on $11 \& 17 / \mathrm{Dec} / 2010$. It covers approximately 408,934 ha and has 17 land cover categories including temperate forests, tropical dry forests, and anthropogenic land cover types. Tropical dry forest is the largest forest category with $24 \%$ of the total coverage. Pine-oak forest is the next largest forest category with approximately $12 \%$ of the coverage (Ghilardi et al. 2012).

The land cover maps of the Monarch Reserve were also generated by visual interpretation of SPOT-5 images obtained on $14 / \mathrm{Feb} / 2010$. It covers approximately 56,259 ha and includes 13 land cover categories. The forest categories were classified into dense, moderately degraded and heavily degraded stages by visually observing the dynamics of vegetation density over multiple dates of 2004, 2006, 2008 and 2010 (Paniagua 2013).

The software and packages that were used to process the data include MRT Tools

(https://lpdaac.usgs.gov/tools/modis_reprojection_tool), DINAMICA-EGO (SOARES-FILHO et al., 2002), Q-GIS (Development Team, 2015) and R (R Core Team, 2013; Bivand y Piras, 2015).

\subsubsection{Forest change detected by annual MODIS PTC} data: Forest changes were detected by analysing annual MODIS PTC data with the conditions presented in table 1. Considering the fluctuation of the PTC values, deforestation pixels are those whose slope value is negative and PTC values in one of the first three time periods are higher than 10, and are lower than 10 in one of the last three time periods. Forest degradation is defined as those pixels whose slope value is negative and at the same time PTC values are higher than 10 . Reforestation is defined as the opposite of deforestation, and the reforestation patches are those pixels with positive slope values, and one of the first three dates of PTC values lower than 10 and one of the last three dates more than 10. Opposite to degradation, pixels of forest regeneration are those whose PTC values in all time-series PTC data are higher than 10 and at the same time have negative slope value.

\begin{tabular}{l|c}
\hline Forest change & Applied conditions \\
\hline Deforestation & $\begin{array}{c}\text { Slope }<0 \text { and }(\text { PTC2000 }>10 \text { or PTC 2001 } \\
>10 \text { or PTC } 2002>10) \text { and }(\text { PTC } 2008<10 \\
\text { or PTC } 2009<10 \text { or PTC 2010 }<10)\end{array}$ \\
\hline
\end{tabular}

\begin{tabular}{l|c}
\hline Degradation & Slope $<0$ and PTC $(2000-2010)>10$ \\
\hline Reforestation & $\begin{array}{c}\text { Slope }>0 \text { and }(\text { PTC } 2000<10 \text { or PTC 2001 } \\
<10 \text { or PTC } 2002<10) \text { and }(\text { PTC2008 }>10 \\
\text { or PTC } 2009>10 \text { or PTC 2010 }>10)\end{array}$ \\
\hline Revegetation & Slope $>0$ and PTC $(2000-2010)>10$ \\
\hline
\end{tabular}

Table 1. Applied conditions for forest cover changes

2.1.2 Verification data: (1) Ayuquila Basin. Forest change verification data were produced by visual interpretation of SPOT-5 images (2004-2010). The original land cover categories were grouped into forest and non-forest and the forest cover change was produced including deforestation, reforestation, and permanence (no change) (table 2). There is no data of degradation and revegetation, since the land cover maps did not include categories of degraded forest.

\begin{tabular}{l|l|l|l}
\hline \multicolumn{2}{c|}{} & \multicolumn{2}{|l}{ Land cover 2010 } \\
\cline { 3 - 4 } \multicolumn{2}{c|}{} & Forest & Non-forest \\
\hline Land cover & Forest & Permanence & Deforestation \\
\cline { 2 - 4 } 2004 & Non-forest & Reforestation & Permanence \\
\hline
\end{tabular}

Table 2. Forest change for Ayuquila Basin (2004 - 2010)

(2) Monarch Reserve. Forest change data were derived for two periods: 2001-2004, and 2004-2010. Firstly, the categories in the land cover maps were grouped into forest, degraded forest, and non-forest. Forest changes were analyzed as shown in table 3 with categories of deforestation, degradation, revegetation, and permanence.

\begin{tabular}{l|l|l|l|l}
\hline \multicolumn{2}{c|}{} & \multicolumn{3}{c}{ Land cover 2010 } \\
\cline { 3 - 5 } \multicolumn{2}{c|}{} & Forest & Degraded forest & Non-forest \\
\hline \multirow{2}{*}{$\begin{array}{l}\text { Land } \begin{array}{c}\text { cover } \\
2001 /\end{array} \\
2004\end{array}$} & $\begin{array}{l}\text { Forest } \\
\text { Degraded }\end{array}$ & Rermanence & Degradation & Deforestation \\
\cline { 2 - 5 } & Non-forest & Reforestation & Permanence & Deforestation \\
\hline
\end{tabular}

Table 3. Forest change for Monarch Reserve

2.1.3 Assessment of MODIS PTC by verification data: The forest change detected by annual PTC data was assessed by comparing with verification data of visual interpretation of SPOT-5 images. A simple overlay operation was adopted as the method and the percentage of overlaying pixels for each change category was used to assess the MODIS PTC data. The higher the percentage of the overlaying pixels, the more reliable the PTC data for forest change detection. 


\section{RESULTS}

3.1 Forest change by annual MODIS PTC data (2000 2010) in Ayuquila Basin

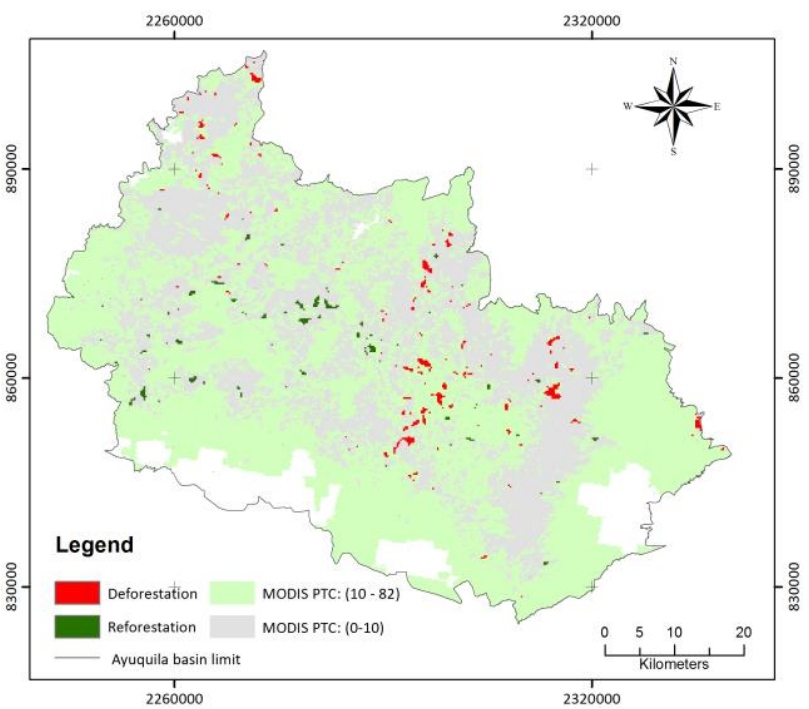

Figure 1. Forest change patches for Ayuquila Basin produced by annual MODIS PTC data $(2000-2010)$ and presented with MODIS PTC 2000 as background.

The detected forest change patches were expressed in number of pixels. The detected deforestation patches were 547 pixels $(0.78 \%)$, and reforestation 291 pixels $(0.41 \%)$. The detected deforestation patches are located in the area of forest in the initial PTC image (2000) and the detected reforestation patches are in the area of non-forest in the initial PTC image (2000).

\subsection{Verification data: forest change by visual interpretation: Ayuquila basin}

Forest cover change maps were produced by a forest cover change model in DINAMICA Ego including categories of deforestation, reforestation, and permanence (figure 2).

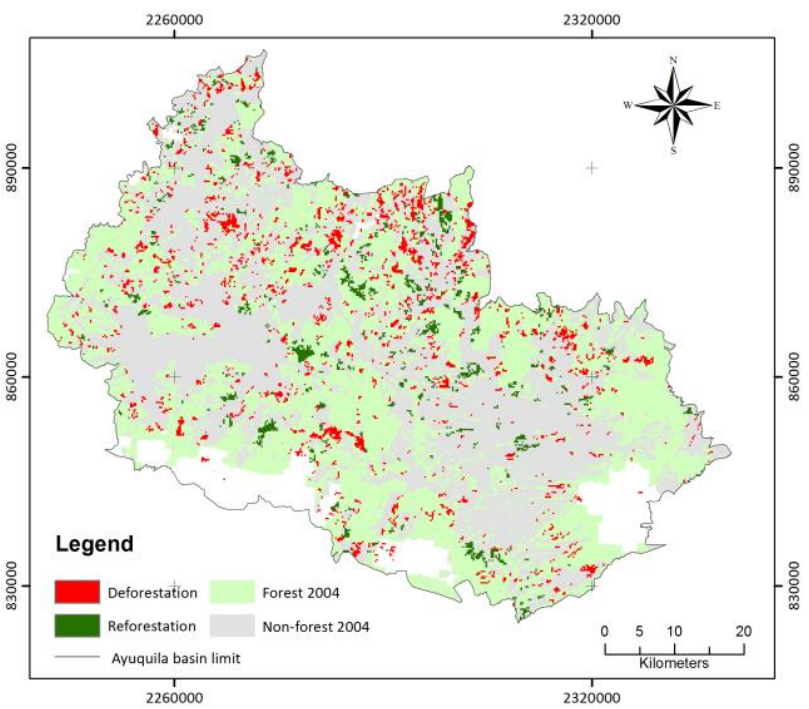

Figure 2. Forest change patches by visual interpretation of SPOT-5 images (2004-2010) and presented with the land cover map 2004 as the background.
With the land cover map 2004 as the background, the detected deforestation pixels were located in forest categories and the detected reforestation pixels located in the non-forest categories. There are 3789 pixels of deforestation, and 1875 pixels of reforestation, with the pixel size resampled to the size of MODIS PTC data.

\subsection{Assessment of MODIS PTC for forest change detection: Ayuquila Basin}

Forest change produced by annual PTC data was compared with the verification data. In quantity, visual interpretation of SPOT5 images detected about four-times more deforestation and reforestation patches than with MODIS PTC data. An overlay analysis found only 33 spatially coincided deforestation pixels, which is $33 / 547=6.03 \%$ in percentage. This overlay analysis did not find overlapping pixels for reforestation.

\subsection{Forest change by annual MODIS PTC data in Monarch Reserve}

The forest change map by MODIS PTC data for Monarch Reserve was presented in Figure 3.

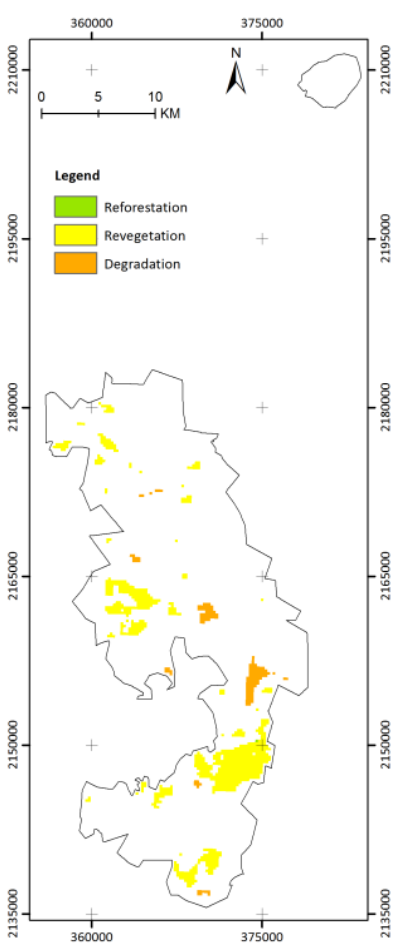

Figure 3. Forest change patches for Monarch Reserve produced by analysis of annual MODIS PTC (2000 - 2010) data.

3.5 Verification data: forest change patches by visual interpretation: Monarch Reserve

Forest change patches by visual interpretation of SPOT images were presented in Figure 4 for the period of $2001-2004$ (left) and $2004-2010$ (right). 


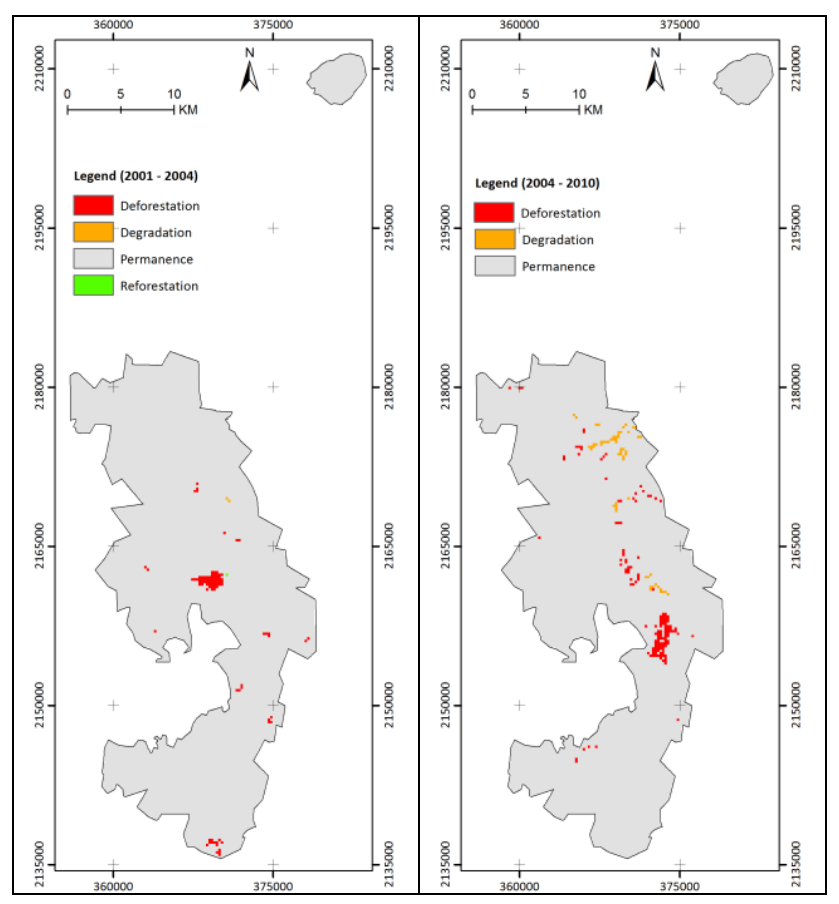

Figure 4. Forest change patches by visual interpretation of SPOT-5 images of Monarch Reserve for the period of 20012004 (left) and 2004-2010 (right).

\subsection{Assessment of MODIS PTC for forest change detection in Monarch Reserve}

Annual MODIS PTC didn't detect deforestation pixels and the verification data did not include revegetation pixels. The pixels of degradation and reforestation by MODIS PTC data don't coincide spatially with those by the verification data.

\section{DISCUSSION AND CONCLUSION}

This study found that while forest change between two dates is relatively easy to label, it is difficult to label forest change with three or more periods of data, especially when data present nonlinear tendencies. The deforestation patches detected by visual interpretation of SPOT images $(2004-2010)$ is roughly 4 times more in quantity than that by PTC data $(2000-2010)$, due to the higher spatial resolution of SPOT images being able to pick up small deforestation patches.

This analysis adopts the concept of forest with more than 10 percent of tree crown cover. Applying to MODIS PTC data, non-forest categories should have PTC values less than 10 . However, Gao et al. (2015) shows that non-forest categories such as high mountain prairies, cultivated agriculture, etc. have PTC values more than 10 (table 4), and thus those pixels were not included as non-forest categories in the analysis with MODIS PTC data. Table 4 shows that there are roughly $1 / 3$ of the non-forest pixels have PTC values more than 10, which also explains why the detected deforestation by annual MODIS PTC data is only a quarter of those detected by visual interpretation $(56.4 / 203.4=27.7 \%)$.

\begin{tabular}{l|l|l}
\hline Land cover 2004 (non-forest) & PTC values & $\begin{array}{l}\text { Percentage in } \\
\text { coverage }\end{array}$ \\
\hline High mountain prairies & 21.1 & $0.15 \%$ \\
\hline Cultivated grassland & 13.9 & $0.68 \%$ \\
\hline
\end{tabular}

\begin{tabular}{l|l|l}
\hline Irrigated agriculture & 11.9 & $8.27 \%$ \\
\hline Induced grassland & 11.8 & $24.13 \%$ \\
\hline Total & - & $33.23 \%$ \\
\hline
\end{tabular}

Table 4. Non-forest categories with PTC values higher than 10 and their coverage in percentage by visual interpretation.

The spatial coincidence of the forest change by MODIS PTC and by visual interpretation is poor (only 6\%). It is necessary to refine the methods for forest change detection with MODIS PTC images; also to refine the validation data in terms of data periods and forest change categories to ensure a better comparison.

\section{REFERENCES}

Bailis, R., Drigo, R., Ghilardi, A., and Masera, O., 2015, The carbon footprint of traditional woodfuels, Nature climate change.

Brower, L., Taylor, O.R., Williams, E.H., Slayback D., Zubieta, R., and Ramirez, M.I., 2011, Decline of monarch butterflies overwintering in Mexico: is the migratory phenomenon at risk? Insect Conservation and Diversity, 1-6.

Corbera, E., Estrada, M., Brown, K., 2010. Reducing greenhouse gas emissions from deforestation and forest degradation in developing countries: revisiting the assumptions. Climatic Change, 100, 355 - 388.

Gao, Y., Ghilardi, A., Paneque-Galvez, J., Skutsch, M., Mas, J.F., 2015, Validation of MODIS vegetation continuous fields for monitoring deforestation and forest degradation: two cases in Mexico. Geocarto International.

Ghilardi, A., Jardel, E., Skutsch, M., Martinez, R., Morfin, J., Allende, T., Vega, E., Morales, J., 2012.Analisis de cambio de cobertura y uso del suelo, escenario de referencia de carbono y diseño preliminar del mecanismo de Monitoreo, Reporte y Verification en los diez municipios de la Junta Intermunicipal de Rio Ayuquila, Jalisco; UNAM. (in Spanish).

FAO, 2011, Assessing forest degradation: Towards the development of globally applicable guidelines, Forest resources assessment working paper 177.

Honey-Rosés, J., 2009, Illegal logging in Common Property Forests, Soceity\& Natural Resources: An International Journal, 22, 916-930.

Jardel, E., Skutsch, M., Morfin, J., Fernandez, A., Morales, L., Ghilardi, A., 2013. Estudio para determinar el estado de degradación y potencial de restauración en ecosistemas forestales bajo manejo de la Cuenca Baja Del Rio Ayuquila Parte 1, Informe final. (in Spanish)

Morales-Barquero, L., Skutsch, M., Jardel-Peláez, E., Ghilardi, A., Kleinn, C., Healey, J., 2014. Operationalizing the Definition of Forest Degradation for REDD+, with Application to Mexico. Forests, 5, 1653 - 1681

Navarrete, J.L., Ramirez, M.I., Perez-Salicrup, D.R., 2011. Logging within protected areas: Spatial evaluation of the 
monarch butterfly biosphere reserve, Mexico. Forest Ecology and Management, 262, $646-654$.

Paniagua, I., 2013. Unidades ambientales y dinámica de cambio en cubiertas del suelo. Geoportal de la reserva de la biosfera mariposa Monarca, Master thesis, UNAM (in Spanish).

SEMARNAT, "Visión de México sobre REDD+", 2010,http://www.conafor.gob.mx:8080/documentos/docs/7/139 3Visi\%C3\%B3n\%20de\%20M\%C3\%A9xico\%20sobre\%20RED D_pdf.

Skutsch, M., Ghilardi, A., Mendoza, M., Morales, L., Borrego, A., The potential for REDD in tropical dry forests, to be submitted to Forest Ecology and Management, in preparation.

Townshend, J.R.G., Carroll, M.,Dimiceli, C., Sohlberg, R., Hansen, M., and DeFries, R., 2011. Vegetation Continuous Fields MOD44B, 2001 Percent Tree Cover, Collection 5, University of Maryland, College Park, Maryland, 2001. (digital data accessed in April 2014 from http://reverb.echo.nasa.gov/reverb/\#utf8=\%E2\%9C\%93\&spatia 1_map=satellite\&spatial_type=rectangle)

UNFCCC (United Nations Framework Convention on Climate Change), 2010, Methodological guidance for activities relating to reducing emissions from deforestation and forest degradation and the role of conservation, sustainable management of forests and enhancement of forest carbon stocks in developing countries. Decision 4/CP.15,

http://unfccc.int/files/na/application/pdf/cop15_ddc_auv.pdf, (accessed 25 August, 2014).

Van der Werf, G.R., Morton, D.C., DeFries, R.S., Olivier, J.G., Kasibhatla, P.S., Jackson, R.B., Collatz, G.J., Randerson, J., 2009. $\mathrm{CO}_{2}$ emissions from forest loss, Nature Geoscience, 2, $737-738$. 